\title{
Determinants of Farmers' Willingness to Participate in Soil Conservation Practices in Jinga Bilu Kebele Gololcha Woreda
}

\author{
Zenebe Reta \\ College of Agriculture and Forestry, Mettu University, P.O. Box 318, Bedelle, Ethiopia
}

\begin{abstract}
This study aimed at identifying determinants of farmer's willingness to participate in soil conservation practice and assessing effects of soil erosion and use of soil conservation practice in the society. Data were collected through structured interview from 75 farmers. Descriptive statistics were used to analyzsis the data, Binary logit model was employed to analyze determinants of farmers' willingness to participate in soil conservation practices. Eight explanatory variables were included in the model of which four were significant at less than $10 \%$ probability levels. The significant variables were age of household head; extension service, technological awareness, and consumer-worker ratio are some of the variables that have significant effect on WTP.specifically, the age of the household have a negative and significant impact on farmers' willingness to participate in soil conservation practices. The assistance of extension agent was affect positively and significantly, the farmers' willingness to participate in soil conservation practices. The dependency ratio also affects negatively and significantly, willingness to participate in soil conservation that is as the number of consumer-worker increases the willingness to participate decrease. Policy makers and government should encourage and provide technical advice to farmers who are practicing soil conservation at their own initiative and using their indigenous knowledge. Researchers should also develop appropriate soil conservation technologies for each particular situation, incorporating farmers' indigenous knowledge. More specifically, as farmers are well adapted to the local ecology and the farming systems, incorporating their indigenous practices would increase acceptability and sustainability of soil conservation
\end{abstract}

Keywords: willingness to participate, soil conservation, participation

DOI: $10.7176 / \mathrm{JEES} / 9-1-01$

\section{INTRODUCTION}

\subsection{Background}

Soil degradation is the big issue and problem internationally. Even in worldwide, it became the main factors for the reduction in agricultural production. Taking into consideration this issue, environmental specialists are taking many measures to reduce its effects. The same things take place in our continent, Africa. The economic development of developing countries depends on the performance of the agricultural sector, and the contribution of this sector depends on how the natural resources managed. Unfortunately, in the majority of developing nations, the quality and quantity of natural resources are decreasing resulting in more severe droughts and floods (Fikru, 2009). In the predominantly agrarian societies of Africa, one of the most threats to food supply is environmental degradation, the deterioration of croplands, grasslands and forests (Alemneh, 2008).

Land degradation and continuous fall in agricultural productivity in countries of SSA have raised serious concerns in the international level. In many agriculture-based developing countries, environmental degradation takes mainly the form of soil nutrient depletion and loss of food production potential. High soil degradation is the main factor for most of African countries called to be poor countries still. Ethiopia is one of the countries in Sub-Saharan Africa faced with pervasive poverty, high rate of population growth, insufficient food production and degradation of natural resource base (World Bank, 2005).

The major cause of land degradation in Ethiopia is erosion (Alemneh, 2008). Intensification of cropping on sloping lands without suitable amendments to replenish lost nutrients has led to widespread degradation of land. Available estimates on the economic impact of soil erosion indicate an annual on- site, average productivity loss of $3.2 \%$ from the 2005 yield level (FAO, 2007).

Land degradation is a major cause of poverty in rural area of developing countries. In many areas, farming population has experienced a decline in real income due to demographic, economic, social and environmental changes. Land degradation is result of several factors of both physical and socio-economic nature. During the past decade, Ethiopia has faced serious ecological imbalance mainly due to a large-scale deforestation, uncontrolled grazing practices, soil erosion caused by improper farming practices and destructive forests exploitation and wildfire. The consequence of which have been a declining agricultural production, water depletion, disturbed hydrological behavior in the river basins, and food insecurity (Daniel, 2007).

The severity of soil erosion in study area (Jinga Bilu) is generally the result of improper soil management, population density and low vegetation cover. In many areas of the kebele, soil erosion is the widespread problems that damage the cultivated lands of the farmers. The conservation measures are implemented in a farm participatory approach. Efforts to install conservation measures on erodible lands initiated following the 1975 
land reform and establishment of peasants associations, which were instrumental in mobilizing labor and assignment of local responsibilities. In order to combat soil degradation and to introduce sustainable use of resources, there is a need to take action.

Soil conservation is very important in subsistent farming system given that soil is the major determinant of output. Following the emerging climate change and increasing population density, the farmer is under pressure to manage the soil. Soil conservation is very technical and scientific. A package of practice (POP) to help solve the soil problem housed in the Jinga Bilu kebele commonly referred to as soil conservation information service. An increasing need for food, fibre and fuel in the kebele, push most farmers into adopting exploitative production techniques, and uncontrolled expansion of/or farming of forest and fragile range areas to increase crop output (ARDA, 2004).

At present, in the study (Jinga Bilu) area is facing extreme soil degradation. The principal factors responsible for the problem include low soil conservation practices and exposure of its topography especially to water fluid, inherent erodible nature of the soils and expansion of farmland. Hence, this study intended to investigate determinants of farmers' willingness to participate in soil conservation practices. Therefore, this study is designed with the following objective.

$\checkmark$ To identify determinants of farmers' willingness to participate in soil Conservation.

$\checkmark$ To assess factors affecting farmer's participation in soil conservation practices

$\checkmark \quad$ To determine effects of soil degradation to production

\section{METHODOLOGY}

\subsection{DESCRIPTION OF THE STUDY AREA}

The study was conducted in Jinga Bilu kebele, which found in Gololcha woreda administration of Oromia regional state. Jinga Bilu kebele is located at the western of golocha town. It is far away about $19 \mathrm{~km}$ from Gololcha town. The area is bounded by choole woreda in the northern, Gololcha woreda in the southern, According to central statistical agency of 2007 , the total population found in kebele is around 2850 peoples, from which 1423 are males and 1427 are females. The peoples of the area have good social relationship. The type of soil that exists in target area is red, black and sandy soil. There are also rivers in the area; that flows for some months per year. Both rivers used for irrigation.

The study area categorized under semi-arid tropical agricultural climatic zone and it accounts an elevation of about $1340-1400 \mathrm{~m}$ above sea level. It lies at longitude of $42^{0 \mathrm{SE}}$ and latitude of $9^{0} 26^{\prime} \mathrm{N}$. The rainfall in the area ranges from $600 \mathrm{~mm}-1260 \mathrm{~mm}$ with the dominant rainfall period that ranges from February-mid may. The maximum and minimum temperature ranges from $6-25^{\circ} \mathrm{c}$ respectively.

The major economic activity of the area is mixed farming system mainly crop production, Coffe and livestock raring. The most commonly cultivated annual crop in the area are; Maize, Sorghum, Tomato and others. Their annual crops are cultivated by subsistence farming in the study area. G selected was, because of its accessibility, access to information and proximity to the campus.

\subsection{TYPE AND SOURCE OF DATA COLLECTION}

Different type of data (qualitative and quantitative data) collected and the data that are relevant to the objective of the study collected were from different sources. The study prepared from both primary and secondary data sources. The primary data collected were from sample of respondents and key informants. The secondary data collected were from experts (natural resource expert), books, statistical reports and official documents.

\subsection{Sampling Size Determination and Sampling Technique}

In the study area, there are 2850 population and 575 household (kebele administration). Due to time, money and other constraints only sample of 75 individual household heads surveyed were, using a random sampling technique. Simple random sampling technique selected was because of population homogeneity

\subsection{Method of Data Collection}

The Data was collected in April month from farm household farmers using a structured interview. The primary data supplemented were by collecting secondary data from relevant sources. The survey intended to collect data and information on various aspects of land degradation, including perception of the degradation problem, its severity, and farmers' willingness to participate conservation practices.

\subsubsection{Contingent Valuation Method}

Contingent Valuation Method (CVM) is a standard approach for valuing non-market resources such as recreation, wild life and environmental quality (Hanemann et al, 1991). It enables economic values descriptive to estimated be for a wide range of commodities not traded in a market. Statistics (frequency distribution, mean, standard deviation, etc.) used were to assess farmers' willingness to participate in soil conservation practices in labor. 


\subsection{Method of Data Analysis}

The quantitative data analysis involved calculation of frequencies, descriptive, binary logistic regression and use of chi-square and odd ratio method to test significance of relationships between farmers' willing participation in the SC(soil conservation) works on the one hand and their age, level of literacy etc.

Descriptive statistics are important to have clear picture of the characteristics of sample units. By applying descriptive statistics one can compare and contrast different categories of sample units (farm households heads) with respect to the desired characteristics. In this study, descriptive statistics, such as mean, standard deviation, percentages and frequency of occurrence used were along the econometric model, to analyze the collected data. The processed data to look for patterns and relationship between and/or among data groups by using descriptive analysis.

\subsubsection{Econometric model specification}

Regression is a method of estimating or predicting a value on some dependent variable given the values of one or more independent variables. Like correlations, statistical regression examines the association or relationship between variables. Unlike correlations, however, the primary purpose of regression is prediction (Geoffrey M. et al., 2005:224-225). In this study, logistic regression employed. This method also takes into account the correlations among the predictor scores (John Adams, et al., 2007:198). They added logistic regression analysis, which means more than one predictor is jointly regressed against the criterion variable.

When any of the explanatory variables in a regression model are binary, one can represent them as dummy variables. Binary choice models assume that individuals faced with a choice between two alternatives and their choice depends on their characteristics. Thus, the purpose of a qualitative choice model is to determine the probability that an individual with a given set of alternatives make one choice rather than the alternative (in this study yes response and no response to the willingness to participate question).

\section{The logit model}

Mathematical expression of the model Where

$$
\mathrm{Li}=\ln \mathrm{P} / 1-\mathrm{p}=\beta_{0}+\beta_{1} \mathrm{x}_{1}+\beta_{2} \mathrm{x}_{2}+\beta_{3} \mathrm{x}_{3}+\beta_{4} \mathrm{x}_{4}+\beta_{5} \mathrm{x}_{5}+\beta_{6} \mathrm{x}_{6}+\beta_{7} \mathrm{x}_{7}+\beta_{8} \mathrm{x}_{8}+\varepsilon \quad \text { (Gujarati, 2004) }
$$

$$
\begin{aligned}
& \mathrm{Ln}=\text { natural logarithm } \\
& \mathrm{P}=\text { probability of Participation } \\
& 1-\mathrm{p}=\text { probability of being non participant } \\
& \beta_{0}=\text { constant term }
\end{aligned}
$$

$\beta_{1}, \beta_{2}, \beta_{3}, \beta_{4}, \beta_{5}, \beta_{6}, \beta_{7}, \& \beta_{8}$, are coefficients of explanatory variables

$\mathrm{x}_{1}, \mathrm{x}_{2}, \mathrm{x}_{3}, \mathrm{x}_{4}, \mathrm{x}_{5}, \mathrm{x}_{6}, \mathrm{x}_{7}$, and $\mathrm{x}_{8}$ are predictor variables included in the model

$\varepsilon=$ error term

Binary explanatory variables can be represented as dummy variables and a binary choice model assumes occurrences between two alternatives (in this case being adopter or non-adopter of improved soil conservation practices). There are several methods to analyze the data involving binary outcomes. However, for this particular study, logit model selected. In logit, model probabilities are bound between 0 and 1 . Moreover, logit best fits to the non-linear relationship between the probabilities and the explanatory variables. The dependent variable in this case is a dummy variable, which takes a value of zero or one depending on whether or not a farmer is adopter or non-adopter of improved soil conservation practices. However, the independent variables are both continuous and binary. In this study, logistic econometric model used was to identify the factors (the independent variables) that affect farmers' decision of adopting improved soil conservation practices in the study area. Farm household heads in Jinga Bilu Kebele differ in the proportion of cultivated land on which different types of physical soil conservation structures are not used. There are non-users of these improved and traditional soil conservation measures.

The Variance Inflation Factor (VIF) used to test for the existence of multi-collinearity between continuous explanatory variables. VIF shows how the variance of an estimator inflated by the presence of multicollinearity (Gujarati, 1995).

The equation of regressions on this study generally built around two sets of variables, namely dependent variable (willingness to participate) and independent variables. Contingency coefficients also calculated were to see the degree of association between the dummy variables.

\section{The Dependent Variable of the Model:}

The dependent variable is a variable or characteristics that affected (dependent) on external factors. In this case, it represents "The factors that affect willingness of farmers to participate in soil conservation practices". The dependent variable for logit analysis has a dichotomous nature measuring the willingness of a farmer to participate in soil conservation practices by contributing labor. It is represented in the model by 1 for a willing farmer and by 0 for a non-willing farmer.

The Independent Variables of the model:

It can be hypothesized as participation in environmental schemes influenced by a set of explanatory variables. 
Based on the findings of past studies on farmers' willingness and decisions on investment and participation in commons, the following variables was hypothesized to determine farmers' willingness to participate in soil conservation practices.

\section{Education level of the household head (EDULEVEL):}

This is a dummy variable, which takes a value 1 if the household head is literate and 0 , otherwise. Education increases farmers' ability to get process and use information it is expected to have a positive effect on willingness to participate for both male and female members of the household.

\section{Age of the household head (Age):}

The effect of a farmer's age on investment decision taken can be as a composite of the effect of farming experience and planning horizon. While longer experience has a positive effect, young farmers on the other hand may have longer planning horizon and hence, may be more likely to invest in conservation.

In this study, age hypothesized was to have a negative influence on the willingness to participate soil conservation activity.

\section{Family size}

This refers to the total number of family members. Imperfections in labor markets imply that households with large human capital may invest more in conservation (Bekele and Holden, 2008). The larger the family, the higher the probability that future generation will farm the land and reap the future benefits of conservation investments (Featherstone and Goodwin, 2003). Thus, in this study family size hypothesized was to have a positive influence on the willingness to participate in soil conservation activity.

\section{Sex of the household head (SEX):}

This is a dummy variable, which takes a value 1 if the household head is male and 0 otherwise. The sex of the household head will be included to differentiate between males and females in their valuation of environmental protection. Tegegne (2004) reported that females as opposed to males tend to participate more in the environmental protection during peak season while males tend to participate more during slack season (season of no agricultural activity).

\section{Assistance in soil conservation practice (ASISTANCE):}

It is a dummy variable, which refers to any form of assistance rendered to the farmers in the area of soil conservation practices. It takes a value 1 if the respondent received any assistance from any source and 0 otherwise. Hence, assistance (material, technical and any other incentives) from any source encourages the farmers to decide on conservation practices and a positive effect hypothesized.

\section{Farmers Awareness About Technology}

A dummy variable, which takes a value 1 if the farmer has taken part in soil conservation activities in the past and 0 otherwise. Knowing available options for soil conservation makes land users to be more receptive to conservation structures (Bekele and Holden, 2008). Therefore, conservation undertaking in the past which is a proxy variable for technology awareness was hypothesized to have a positive effect on the willingness to participate in conservation works.

7. Dependency Ratio in Family: An increase in consumer-worker ratio (dependency ratio) reduces the ability to meet subsistence needs, and increase the personal rate of time preference (Bekele and Holden, 2008). This variable expected to have a negative effect on farmers' willingness to participate in soil conservation activities.

\section{Distance of Farm from Living House}

Distance is a continuous variable that affects farmer's participation in soil conservation practices. It can be proposed that distance to be negatively related to participation.

In this study willingness to participate in soil conservation practice motivate were by engaging farmer's ingroup arrangements. This group arrangement performs terrace, counter bund, planting of trees on owned lands.

\section{RESULTS AND DISCUSSION \\ Descriptive results and analysis \\ Demographic characteristics of the sample household head}

Age is an important factor that must be considered in any given business activity (either in agriculture or in industrial sector). It is clear that elders cannot perform hard works, for example participating in soil conservation practices. Age is a continuous variable that can be analyzed by descriptive statistics. the mean value of 75 respondent is 43 year, where it's minimum value $=19$ year and the maximum value $=65$.

The survey results show also that $54.7 \%$ and $45.3 \%$ of the sample respondents were males and females, respectively. From the total household heads willing to participate in soil conservation measures about $44.11 \%$ were females and from total females surveyed about $55.89 \%$ reported were to be unwilling to participate. On other hand out of total male respondents surveyed about $51.22 \%$ reported were to be willing to undertake the activity. Contrary $48.78 \%$ of total male were unwilling to participate in soil conservation.

The survey result shows that $91 \%$ of the sample farmers were married while $2 \%$ and $7 \%$ widowed and divorced respectively. 
The survey results show that $50.7 \%$ of the total surveyed farmers were literate (with 1 value), and $49.3 \%$ were illiterate (with 0 value). From the size of total participants or respondents, $15.79 \%$ were educated and willing to perform exercises. However, even they were educated $84.2 \%$ were not willing to undertake soil conservation practices. From data collected, about $86.48 \%$ respondents were willing to participate and illiterate. The remaining, $13.52 \%$ were not educated and not willing to participate.

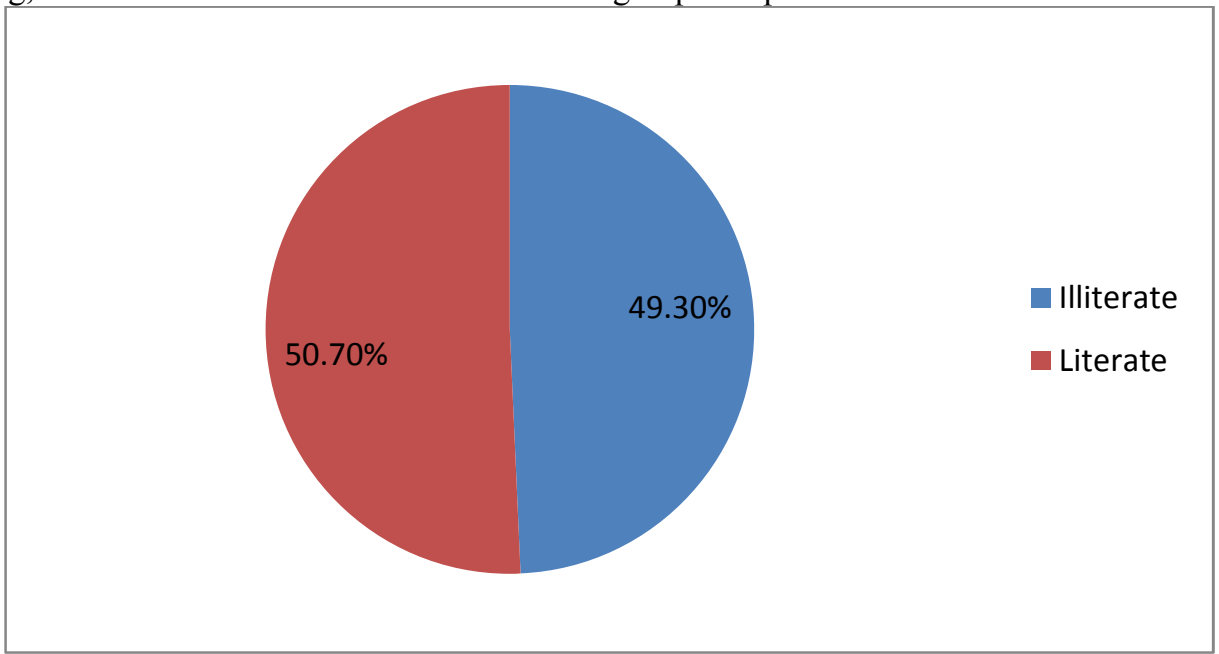

The average family size of the sample farmers was about 7persons. This average masks differences in family size, where the largest family size was 12 and the smallest was 2

With regard to religious affiliation, $100 \%$ of the respondents were Muslims throughout the survey.

A. RESOURCE BASIS

The total land coverage of the surveyed is about 125 ha, from this 20 ha grazing land, 10 is shrub land, and the rest, 95ha is cultivated land.

Cropping system and input utilization

The major economic activity of the area is mixed farming system mainly crop production and livestock raring. The most commonly cultivated crop in the area are; Maize, Sorghum, Tomato and others.

They use their inputs as much possible based on advices given from extension agent. They use fertilizer and others like compost to increase their production.

Agricultural extension services provided by extension agent believed to be important sources of information about improved agricultural technologies.

About $56 \%$ of the sample respondents responded that they had contact with agricultural extension agents, either in groups or individually per each meeting every week.

Frequency of Extension contact with sample HH/week

\begin{tabular}{|l|l|l|}
\hline Response & Contact per week & Percent \\
\hline YES & 42 & 56.00 \\
\hline NO & 33 & 44.00 \\
\hline Total & 75 & 100.0 \\
\hline
\end{tabular}

Source: Survey data

Almost all household heads had contact with extension agents on matters related to general agricultural practices during meeting per week. According to the sample respondents who had contact with extension agents, they had contact with extension agents on matters related to soil conservation and issue of another discussion. Though the magnitude of soil degradation intensified in the area, it is only recently that extension agents have started to give emphasis to soil conservation issues. About $80.95 \%$ of willing respondents had contacts with extension agents per meeting. Similarly about $19.05 \%$ of the non-willing respondents had also gained extension assistances. Still $90.9 \%$ of unassisted respondents were willing to participate, where $9.1 \%$ are neither assisted nor willing to participate.

However, their contact with extension was not the same throughout all the year, rather there was more contacts in spring, summer and harvesting season. Households in the kebele undertake their activities even in mass or they have association in which they perform their soil conservation measures jointly to be effective and efficiently use their resources.

From75 sample respondents 38 reported that they were willing to participate in soil conservation activities, whereas the remaining ( 37 respondents) reported that they were not willing to undertake any conservation work. 
Frequency of participants and non-participants

\begin{tabular}{|l|l|l|}
\hline & Frequency & Percent \\
\hline Willing & 38 & 50.7 \\
Unwilling & 37 & 49.3 \\
Total & 75 & 100.0 \\
\hline
\end{tabular}

The average dependency ratio was about 1.064, which shows that each economically active person in a household supports about one economically inactive person.

About $54.7 \%$ of the respondents responded that they knew the existence soil conservation activities, the major sources of information being extension agents, where about $45.3 \%$ did not know from their response. Out of total households with awareness about technology, $19.5 \%$ were willing to participate and about $80.5 \%$ were not having willing. At value of $88.24 \%$ the respondent were willing, but not having awareness. From the total respondents $11.76 \%$ were did not have neither awareness nor willing to perform soil conservation measures .

\subsection{Factors affecting farmer's willingness to particippate in SCP}

Prior to running the logistic regression model, the explanatory variables checked were for existence of multicollinearity and the degree of association. Accordingly, a technique of Variance Inflation Factor (VIF) employed was to detect the problem of multicollinearity among the continuous variables.

The existence of multicollinearity problem between continuous variables was detected by variance inflation factor (VIF); whereas, contingency coefficient (C) was employed to detect multicollinearity problem between discrete explanatory variables. Mathematically:

$\mathrm{VIF}_{\mathrm{J}=1 / 1-\mathrm{R}}{ }^{2}$ Where; $\mathrm{R}^{2=}$ Coefficient of determination

$\mathrm{VIF}_{\mathrm{j}}=$ Variance Inflation Factor

Based on the VIF (Xi), the data had no serious problem of multicollinearity. This is because, for all continuous explanatory variables, the values of VIF are by far less than 10 (Appendix6). Therefore, all the continuous explanatory variables were included in the model.

Multicollinearity is a research problem that exists when the relationship between explanatory variables are perfect. The sign of Multicollinearity problem for continuous variable is high when VIF $\geq 10$. Similarly, the contingency coefficients, which measure the association between various discrete variables based on the chisquare, computed were in order to check the degree of association among the discrete variables. The values of contingency coefficient ranges between 0 and 1, with zero indicating no association between the variables and values close to 1 indicating a high degree of association. Accordingly, the results of the computation reveal that there was no serious problem of association among discrete explanatory variables. Hence, all the 4 discrete variables were entered into logistic analysis.

Table of logistic regression below represents the signs, magnitudes, and statistical significance of the estimated parameters and how much the observed values correctly predicted by the logistic regression model. Coefficient of determination, one of measure of goodness of fit showed to be good model with value of $78.10 \%$. This means that the explanatory variables in model to explain at $78.10 \%$ the dependent variable, willingness to participate in soil conservation practice in case of this study. The remaining variables that not mentioned were corresponding to $21.9 \%$, which could affect the willingness of farmers' participation in soil conservation practices.

Note: Chi-square is goodness of fit test that applied when categorical variables existing in the data. This test used especially when the applied sampling technique is simple random sampling. The large chi-square shows an association between dependent and specific independent variables and small P-value $(\mathrm{p}<0.05)$. Small chi-square implies no association between variables. For instance from the result one can observe that there is an association between all the significant variables, hence it was 38.18, 35.12, 29.59, and 10.044 for extension service, awareness, age and consumer-worker ratio respectively with willingness to participate in soil conservation practices .

Z-value: Is the test of statistical significance that helps to decide whether or not reject the null hypothesis. The measure of standard deviation and shows how much the standard deviation away from the mean.

The t-value: Shows the degree of association between dummy variables. The absolute value of t-value greater than 1.64 shows the significant association between variables. For age that is less than 42 and more than 43 there is significant difference about participation. The same discussion belongs to consumer-worker ratio of less or equal to one and greater than one regarding willingness of farmers to participate in soil conservation practices .

As discussed earlier, the logit model used was to analyze determinants of farmers' willingness to participate in soil conservation practices. The farm household is either willing or not willing to participate in soil conservation practices. Consequently, the variable willingness to participate in soil conservation practices by 
contributing labor was used as a binary dependent variable taking a valuel indicating the willingness of the farmer to contribute labor and 0 otherwise.

Eight explanatory variables (four continuous and four dummy) were included in the regression. Summary of explanatory variables included in the logistic regression model given below.

\subsection{Discussion on Significant Explanatory Variables}

The logistic regression model shows that out of the eight variables hypothesized to determine willingness of farmers' to participate in soil conservation practices, 4 were statistically significant at less than $10 \%$ probability level. More specifically, the coefficients of age of the household head, technological awareness, institutional assistance, and dependency ratio were significant. Out of the eight explanatory variables hypothesized to explain the willingness of farmers' to participate in soil conservation practices in the study area, 4 were found to be significant at less than $0.09 \mathrm{p}$-value.

The coefficients of 4 variables were not statistically significant at the conventional probability levels implying that they were less important in explaining the variability in the willingness to participate in soil conservation practices. These variables were sex of the household head, education level, distance, and family size. The significant explanatory variables are the followings with discussion about them. Discussion of Discrete Explanatory Variable Logistic regression

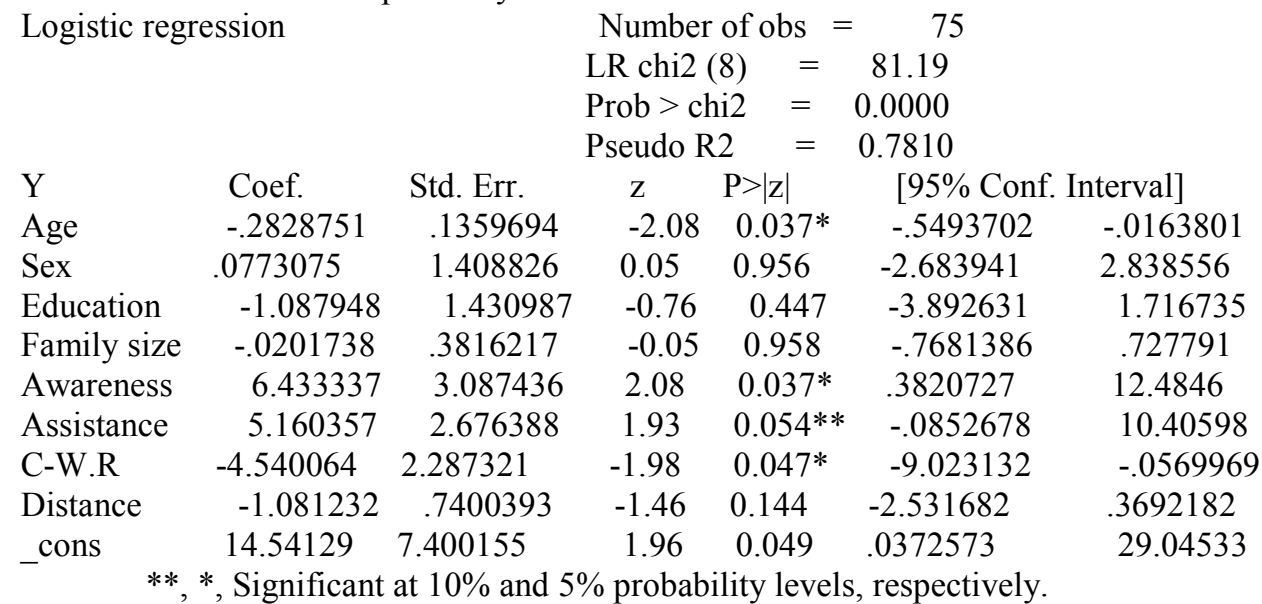

Soil Conservation Undertaking In The Past (Awareness): This variable positively and significantly related with the dependent variable. In other words, soil conservation undertaking in the past, which is a proxy for technology awareness, affected farmers' willingness to participate in soil conservation practices as expected.

The coefficient of this variable was significant at 5\% probability level. Peasants' awareness of technology attributes increases their willingness to use it. Technological awareness is a dummy variable as stated. Its interpretation differs from that of continuous variable.

In interpretation of continuous variable, the interpretation depends on magnitude of coefficient in logistic regression result. However, for dummy the antilog of magnitude of coefficient corresponding to dummy under consideration is used. Therefore, the interpretation follows the odds ratio in favor of showing interest to participate in soil conservation practices increases by a factor of 622.24 for farmers who undertook soil conservation activities in the past.

Assistance in Soil Conservation Practice (Assistance): This is a dummy variable that indicates any form of support (material, technical, financial and other types of incentives) provided to farmers with a view to encouraging them to use soil conservation measures. As noted earlier, physical soil conservation measures are labor intensive and require financial and material inputs, which farmers may not be able to afford. As a result, assistance from any source encourages farmers to adopt physical conservation measures. In the same manner, this explanatory variable became the important variable in explaining farmers' willingness to participate in soil conservation measures of this study. It positively related to the stated dependent variable at $10 \%$ probability level (less powerful in explaining farmers' willingness to participate in soil conservation practices, as their coefficients were significant at $10 \%$ significance level). The odds ratio in favor of showing interest to participate in soil conservation practices increases by a factor of 174.22 for farmers who had extension service.

\section{Discussion of Continuous Explanatory Variables}

Age of household head: Age an important factor that must be considered in any given business activity (either in agriculture or industrial sector). It is clear that elders cannot perform hard works, say participating in soil conservation practices in case of this study. Scientifically active age group person can perform actively any operation. From the result of regression age is negatively related to farmers' participation in soil conservation practices. Age is significant at 5\% probability level. The odds ratio in favor of showing interest to participate in 
soil conservation practices decreases by a factor of 1.33 as age of farmer's increases by one year, keeping other variables constant.

Dependency Ratio: The consumer-worker ratio is another significant factor in this model of the study. The coefficient of this variable was also significant at 5\% probability level. Dependency ratio negatively related to willingness of farmer about performing soil conservation measures. That means the high the consumer worker ratio in a given family implies the lower the participation of that household. Other factors being kept constant, the odds ratio, in favor of showing interest to participate in soil conservation practices decreases by a factor of 93.72 as the consumer-worker ratio increases by one person.

\section{Conclusions and Recommendations.}

Agricultural development in Ethiopia hampered by many factors among which land degradation is the major one, which is threatening the overall sustainability of agricultural production of the country. The major cause of land degradation in Ethiopia is erosion. Land degradation can be defined as a process that lowers the current and future capacity of the land to support human life Land degradation is result of several factors of both physical and socio-economic nature. The consequence of which have been a declining agricultural production, water depletion, disturbed hydrological behavior in the river basins, and food insecurity. Economic losses arising from soil degradation may be divided into on-site and off-site costs. On-site costs refer to the direct effects of soil degradation on the quality of the land resource itself, often expressed in terms of reduced agricultural productivity. Off-site costs refer to the indirect effects of soil degradation, and usually take the form of externalities. The severity of soil erosion in Jinga Bilu kebele is similarly the result of improper soil management, high rainfall and population density and low vegetation cover, low soil conservation practices and exposure of its topography especially to water fluid, inherent erodible nature of the soils and expansion of farmland by clearing forest.

It believed that technological innovations combined with scientific methods were the answers to soil erosion problems. In response to the extensive degradation of land, Ethiopia has taken some efforts to mitigate the problem of soil erosion and enhance or at least to maintain the existing production potential of the land at different times. Improved soil conservation technologies introduced and promoted in some degraded areas of the Jnga Bilu kebele of Gololcha woreda through the ministry of agriculture.

This study conducted, therefore, to examine how smallholder farmers are trying to meet soil conservation problems and what determines to undertake conservation measures. To achieve the objectives of this study, logit model analysis using 75 sample household farmers selected used in addition to secondary data collected from different institutions.

Farmers in Jinga Bilu kebele used mostly traditional soil conservation measures, like the terrace, counter bund...etc. Based on the result of this study awareness about technology, extension services given, consumerworker ratio and age significantly affected the probability and intensity of participating in soil conservation measures.

The principal objective of this study was to identify and analyze the determinants of farmers' willingness to participate in soil conservation practices in Jinga Bilu kebele. More specifically, the study designed was to identify the variables, which determine farmers' willingness to participate in soil conservation practices and find out how each variable related to the willingness of farmers to participate in soil conservation practices. The study also intended to determine the relative importance of participating in soil conservation practice.

The data used for the study collected were from 75 farm household heads drawn from the upper Jinga bilu kebele. Primary data collected were using a structured interview. In addition, secondary data extracted were from relevant sources to supplement the data obtained from the survey.

A binary logit model and descriptive statistics employed were to determine the effect of different explanatory variables on farmers' willingness to participate in soil conservation practices. Four variables hypothesized to explain farmers' willingness to participate in soil conservation practices used were to estimate the econometric model. The results of binomial logit model reveal that the coefficients of four variables were significant at less than $10 \%$ probability level. The remaining variables were less powerful in explaining farmers' willingness to participate in soil conservation practices. The significant variables included age household, technological awareness about soil conservation, assistance of extension agent, and consumer-worker ratio.

The age of the household head found was to have a negative and significant impact on farmers' willingness to participate in soil conservation practices, implying that as the age farmers increase willingness to participate in soil conservation were decrease. Technological awareness of soil erosion problem positively and significantly related to the farmers' willingness to participate in soil conservation practices. This implies that farmers' recognition of soil erosion hazard is very important for their decision to participate in soil conservation activities.

The assistance of extension agent was affect positively and significantly, the farmers' willingness to participate in soil conservation practices. The dependency ratio also affects negatively and significantly, willingness to participate in soil conservation that is the number of consumer-worker increases the willingness to 
participate decrease.

Four variables were not significant at the conventional probability levels. These variables include education level, distance, family size of household and sex. Therefore, the following points are recommended.

$\checkmark \quad$ Researchers should also develop appropriate soil conservation technologies for each particular situation, incorporating farmers' indigenous knowledge. More specifically, as farmers are well adapted to the local ecology and the farming systems, incorporating their indigenous practices would increase acceptability and sustainability of soil conservation measures.

$\checkmark \quad$ Local people should be allowed to participate in any activity that concerns them. Therefore, there should be an effort, from policy makers, aimed at enhancing the awareness of these farmers.

$\checkmark \quad$ In this kebele, farms of elders are being exposed to erosion. This is mainly due to elders cannot participate and so government should observe problems of such non-participant household heads and conserve the resources.

$\checkmark$ Government should train farmers about family planning; hence, consumer-worker ratio negatively affected the participation activity.

\section{REFERENCES}

* Abu, et al (2011), determinants of farmer's willingness to participate in soil management.

* Agriculture and rural development authority (ARDA), 2004, Proximate Determinants of farmers for soil conservation practices.

* Alemneh Dejene, 2008. Environment, Famine, and Politics in Ethiopia: A View from the Village. Lynne Rienner Publishers, Inc.

* Anemut, B. (2006).Determinants of Farmers Willingness to Pay for the Conservation of National Parks. The Case of Simen Mountains National Park. MSc. Thesis, Haramaya University. Haramaya, Ethiopia.

* Ayalneh, B. (2006). Land Degradation, Impoverishment and Livelihood Strategies of Rural Households in Ethiopia: Farmers' Perceptions and Policy Implications. PhD Dissertation, Umboldt University, Berlin, Germany.

* Baidu-Forson, J. (2009). 'Factors Influencing Adoption of Land Enhancing Technology in the Sahel: Lessons from a Case Study in Niger'. Agricultural Economics. The Journal of the International Association of Agricultural Economists (IAAE), Vol. 20, NO.3, pp.231-240.

* Bekele Shiferaw and Holden, S.T. 2008. "Resource Degradation and Adoption of Land Conservation Tsechnologies in the Ethiopian Highlands": A case Study in Andit Tid, North Shewa. The Journal of the International Association of Agricultural Economists , 18(18), 233-247.

* Campbell, J. 2004. "Land or Peasants?" The Dilemma Confronting Ethiopian Resource Conservation.' African Affairs 90, 5-21.

* Daniel, D., 2007. Soil and water conservation Manual/Guideline for Ethiopia. Soil and Water conservation Team, Natural Resources Management and Regulatory Department, Ministry of Agriculture, Addis Ababa, Ethiopia.

* Demeke, B. (2008). Economics of Soil Erosion and Conservation. Review of Literature and a Dynamic Non-linear Optimization Model with Risks and Uncertainties: A Case Study for Ethiopia. M.Sc. Thesis in Environmental Economics. Wageningen Agricultural University

* Ervin, C.A., and Ervin, E.D. 2002. "Factors Affecting the Use of Conservation Practices": Hypothesis, Evidence and Policy Implications. Land Economics, 58(3), 97-307.

* FAO. 2007. Incentives for Community Involvement in Conservation Programs. No. 12, Rome. FAO (2004). Land Degradation in South East Asia: Its Severity, Causes and Effects up on the People, Rome

* Fikru, A. (2009). Assessment of Adoption Behaviour of Soil and Water Conservation Practices in the Koga Watershed, Highlands of Ethiopia. MSc. Thesis, Cornell University.

* Geoffrey Marczyk, David DeMatteo and David Festinger. (2005). Essentials of ResearchDesign and Methodology. Canada, John Wiley \& Sons, Inc.

* Grupperud, S. 2006. "Population Pressure and Land Degradation": The Case of Ethiopia. Journal of Environmental Economics and Management 30, 18-33.

* Gujarati, D.N. 1995. Basic Econometrics. 3 rd Edition. McGraw-Hill, Inc.

* Holden, S.T., Shiferaw, B., Wik, M. 2008. "Poverty, Market Imperfections and Time Preference": Of Relevance for Environmental Policy. Environmental and Development Economics 3, 105-130.

* Housing Census of Ethiopia. Various Statistical Abstracts, Addis Ababa.

* Lucila, M., Lapar, A. and Pandy, S. 2009. "Adoption of Soil Conservation: The Case of Philippine Uplands". The Journal of the International Association of Agricultural Economists, 2(3).

* Lynne, G.D., Shonkwiler, J.S. and Rola, L.R. 2008. “Attitudes and Farmers Conservation Behaviour". American Journal of Agricultural Economics 70, 12-19. 
* Pagiola S (2004b). Quantifying the returns to soil conservation in Kenya. Paper Presented at Soil and Water Conservation Society.Baltimore.

* Sureshwaran, S. R. Londhe and P. Franzier, 2009. "A Logit Model for Evaluating Farmer Participation in Soil Conservation Programs": Slopping Agricultural Land Technology on Upland Farms in the Philippines. Journal of Sustainable Agriculture , 7(4), 52-69.

* Tegegne Gebere Egziabher, 2004. "Willingness to Pay for Environmental Protection": An Application of Contingent Valuation Method (CVM) in Sekota District, Northern Ethiopia. Ethiopian Journal of Agricultural Economics , 3(1), 123-

* Wegayehu, B. (2009). Economics of Soil and Water Conservation. Theory and Empirical Application to Subsistence Farming in the Eastern Ethiopian Highlands: A doctoral Thesis. Swedish University of Agricultural Sciences. Uppsala, 2009.

* World Bank, 2005. Development and the Environment. Oxford University Press, Oxford, for World Bank, Washington 